\title{
Optical Properties of AlGaN Quantum Well Structures
}

\author{
Hideki Hirayama $^{1}$, Yasushi Enomoto ${ }^{12}$, Atsuhiro Kinoshita ${ }^{12}$, Akira Hirata $^{2}$ and \\ Yoshinobu Aoyagi ${ }^{1}$ \\ ${ }^{1}$ The Institute of Physical and Chemical Research (RIKEN), \\ 2-1, Hirosawa, Wako-shi, Saitama, 351-0198, Japan, hirayama @postman.riken.go.jp \\ ${ }^{2}$ Department of Chemical Engineering, Waseda University, \\ 3-4-1, Okubo, Shinjuku-ku, Tokyo, 169-8555, Japan
}

\section{ABSTRACT}

We demonstrate 230-250 nm efficient ultraviolet (UV) photoluminescence (PL) from AlN(AlGaN)/AlGaN multi-quantum-wells (MQWs) fabricated by metalorganic vapor-phase-epitaxy (MOVPE). Firstly, we show the PL properties of high Al content AlGaN bulk (Al content: 85-95\%) emitting from near band-edge. We systematically investigated the PL properties of AlGaN-MQWs consisting of wide bandgap AlGaN (Al content: 53-100\%) barrier. We obtained efficient PL emission of 234 and $245 \mathrm{~nm}$ from $\mathrm{AlN} / \mathrm{Al}_{0.18} \mathrm{Ga}_{0.82} \mathrm{~N}$ and $\mathrm{Al}_{0.8} \mathrm{Ga}_{0.2} \mathrm{~N} / \mathrm{Al}_{0.18} \mathrm{Ga}_{0.82} \mathrm{~N}$ MQWs, respectively, at $77 \mathrm{~K}$. The optimum value of well thickness was approximately $1.5 \mathrm{~nm}$. The emission from the AlGaN MQWs were several tens of times stronger than that of bulk $\mathrm{AlGaN}$. We found that the most efficient PL is obtained at around $240 \mathrm{~nm}$ from AlGaN MQWs with $\mathrm{Al}_{0.8} \mathrm{Ga}_{0.2} \mathrm{~N}$ barriers. Also, we found that the PL from AlGaN MQW is as efficient as that of InGaN QWs at $77 \mathrm{~K}$.

\section{INTRODUCTION}

$\mathrm{AlN}$ or $\mathrm{AlGaN}$ is very attractive material for the application to ultraviolet (UV) laser diodes (LDs), light-emitting diodes (LEDs) or photo detectors, because the direct transition energy can be adjusted between $6.2 \mathrm{eV}(\mathrm{AlN})$ and $3.4 \mathrm{eV}(\mathrm{GaN})$. UV LDs or LED are expected to realize the large capacity optical memories or compact UV measurement systems. Recently, the efficient UV light sources are expected in the field of chemical industry or medical applications.

However, there are some large problems preventing us from achieving UV optical devices. The most serious problems are difficulty to obtain efficient UV emission from AlGaN quantum wells (QWs), in contrast to InGaN QWs, and hole injection through high $\mathrm{Al}$ content (more than 30\%) AlGaN alloy. Recently some research groups reported on the approaches to realize UV optical devices using GaN or AlGaN materials $[1,2]$. We have already achieved $333 \mathrm{~nm}$ current injection emission from $\mathrm{Al}_{0.03} \mathrm{Ga}_{0.97} \mathrm{~N} / \mathrm{Al}_{0.25} \mathrm{Ga}_{0.75} \mathrm{~N}$ QWs using $\mathrm{Mg}$-doped AlGaN/GaN super-lattice hole conducting region [3].

The purpose of this work is to obtain efficient UV emission as well as blue emission already obtained from InGaN QWs. Last year, we have obtained $280 \mathrm{~nm}$ intense photoluminescence (PL) emission from AlGaN QWs at $77 \mathrm{~K}$ [4]. Also, we reported on the PL enhancement in GaN/AlGaN QWs induced by Si-doping due to the compensation of large piezoelectric field in the well [5].

In this work, we demonstrate the first intense UV PL around $230 \mathrm{~nm}$ from AlGaN multi-quantum-wells (MQWs) consisting of high Al content AlGaN or AlN barriers. We obtained the growth condition of high Al content AlGaN. We obtained a single peak spectrum from high $\mathrm{Al}$ content $\mathrm{AlGaN}$ bulk (Al content up to $80 \%$ ) emitting 
from the near band-edge. Then we fabricated AlGaN-MQWs consisting of wide bandgap AlGaN (Al content: 53-100\%) barriers. The well thickness dependence of PL properties is systematically investigated. We show efficient emission around $230 \mathrm{~nm}$ obtained from the AlN/AlGaN MQWs. Finally, the PL intensities are compared between AlGaN MQWs with various $\mathrm{Al}$ content of $\mathrm{AlGaN}$ barriers, and $\mathrm{InGaN}$ and $\mathrm{GaN}$ QWs.

\section{EXPERIMENTS AND DISCUSSIONS}

The samples were grown at 76 Torr on the Si-face of an on-axis $6 \mathrm{H}$ $\mathrm{SiC}(0001)$ substrate, by a conventional horizontal-type MOVPE system. As precursors ammonia $\left(\mathrm{NH}_{3}\right)$, trimethylaluminum (TMAl), and trimethylgallium (TMGa) were used with $\mathrm{H}_{2}$ as carrier gas. $\mathrm{N}_{2}$ gas was independently supplied by a separate line in order to control the gas flow. Typical gas flows were 2 standard liters per minute (SLM), 2 SLM, and $0.5 \mathrm{SLM}$ for $\mathrm{NH}_{3}, \mathrm{H}_{2}$, and $\mathrm{N}_{2}$, respectively. The molar fluxes of TMGa and TMAl for the growth of $\mathrm{Al}_{\mathrm{x}} \mathrm{Ga}_{1-\mathrm{x}} \mathrm{N}(\mathrm{x}=0.11-1)$ were 38 and 2.6-45 $\mu \mathrm{mol} / \mathrm{min}$, respectively. At this condition, the growth rate of $\mathrm{Al}_{0.11} \mathrm{Ga}_{0.89} \mathrm{~N}, \mathrm{Al}_{0.40} \mathrm{Ga}_{0.60} \mathrm{~N}$ and $\mathrm{AlN}$ were approximately $2.4,1.0$ and $0.4 \mu \mathrm{m} / \mathrm{h}$, respectively. The substrate temperature measured with a thermocouple located at the substrate susceptor during the growth was $1140{ }^{\circ} \mathrm{C}$ for all layer. All samples were undoped.
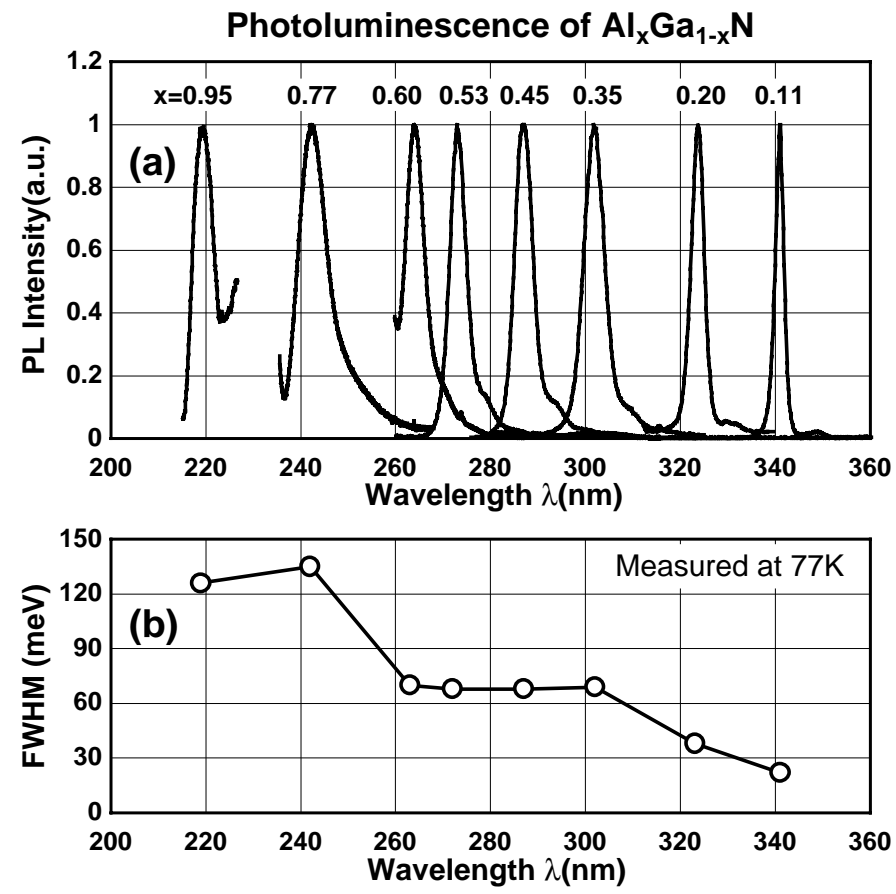

Figure 1. PL spectra of $A l_{x} G a_{1-x} N(x=0.11-0.95)$ films grown on 6H-SiC measured at 77 K. 


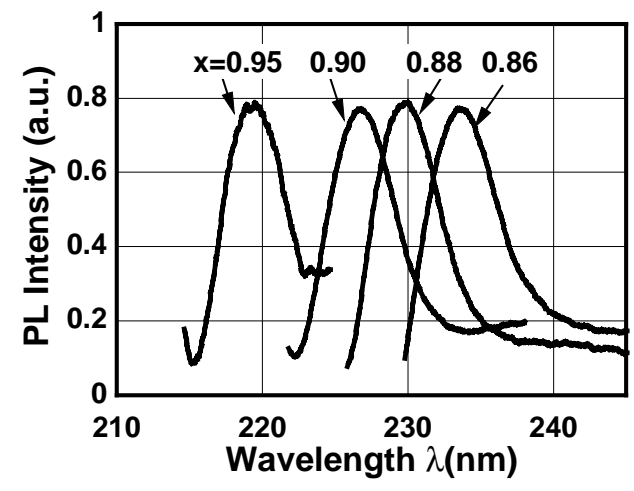

Figure 2. PL spectra of high Al content $A l_{x} G a_{1-x} N(x=0.86-0.95)$ films measured at $77 \mathrm{~K}$.

At first, we show the optical properties of high Al content AlGaN alloy. Figure 1 shows (a) the PL spectra and (b) full width at half maximum (FWHM) of the PL peak of AlGaN films measured at $77 \mathrm{~K}$. The AlGaN alloy was grown directly on a very thin $(\sim 5 \mathrm{~nm})$ AlN layer deposited on SiC. Figure 2 also shows the PL spectra of high Al content $\mathrm{AlGaN}$ ( $\mathrm{Al}$ content is $85-95 \%$ ). The thickness of $\mathrm{AlGaN}$ film was approximately 250 and $400 \mathrm{~nm}$ for $\mathrm{AlN}$ and $\mathrm{Al}_{0.11} \mathrm{Ga}_{0.89} \mathrm{~N}$, respectively. As seen in Fig. 1 and 2, single peak spectra were obtained for Al contents of 0.11-0.95 emitting from near band edge. The yellow emission around 500-550 nm was negligible even for high Al content AlGaN. The phonon-replica peaks are seen at the low energy side of each spectra for Al content of $0.11-0.53$, confirms the good crystal quality of the AlGaN. The typical value of FWHM of the spectrum was approximately 20, 65 and $120 \mathrm{meV}$ for the Al content of 10$12 \%, 35-60 \%$ and $70-95 \%$, respectively. The increased FWHM observed for the Al content of $35-60 \%$ may be due to the layer composition fluctuation during the growth. The large FWHM (120 meV) observed for high Al content AlGaN indicates that at this moment the crystal quality of AlN is not so good compared with that of GaN.

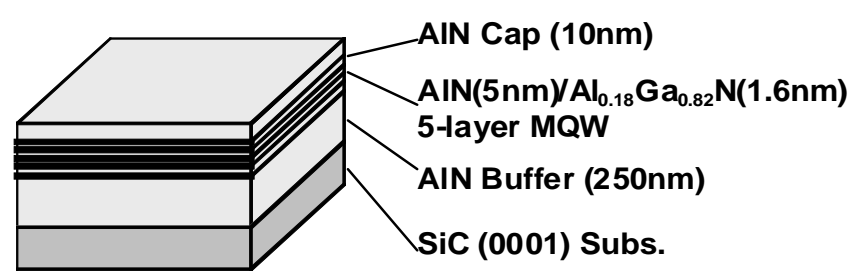

Figure 3. Schematic layer structure of fabricated $A l N / A l_{0.18} G a_{0.82} N M Q W$ sample. 
Table I. Material and the thickness of buffer, barrier, well layers, and PL peak wavelength range of each series of AlGaN MQWs.

\begin{tabular}{|c|l|c|c|c|c|}
\hline $\begin{array}{c}\text { Sample } \\
\text { Series }\end{array}$ & Structure & $\begin{array}{c}\text { Buffer } \\
\text { (Thickness) }\end{array}$ & $\begin{array}{c}\text { Barrier } \\
\text { (Thickness) }\end{array}$ & $\begin{array}{c}\text { Well } \\
\text { (Thickness) }\end{array}$ & $\begin{array}{c}\text { Peak } \\
\text { Wavelength }\end{array}$ \\
\hline (a) & 5-layer MQW & $\begin{array}{c}\mathrm{AlN} \\
(250 \mathrm{~nm})\end{array}$ & $\begin{array}{c}\mathrm{AlN} \\
(5 \mathrm{~nm})\end{array}$ & $\begin{array}{c}\mathrm{Al}_{0.18} \mathrm{Ga}_{0.82} \mathrm{~N} \\
(1.2-3.3 \mathrm{~nm})\end{array}$ & $229-285 \mathrm{~nm}$ \\
\hline (b) & 5-layer MQW & $\begin{array}{c}\mathrm{Al}_{0.8} \mathrm{Ga}_{0.2} \mathrm{~N} \\
(250 \mathrm{~nm})\end{array}$ & $\begin{array}{c}\mathrm{Al}_{0.8} \mathrm{Ga}_{0.2} \mathrm{~N} \\
(5 \mathrm{~nm})\end{array}$ & $\begin{array}{c}\mathrm{Al}_{0.18} \mathrm{Ga}_{0.82} \mathrm{~N} \\
(0-3.3 \mathrm{~nm})\end{array}$ & $238-288 \mathrm{~nm}$ \\
\hline (c) & 5-layer MQW & $\begin{array}{c}\mathrm{Al}_{0.7} \mathrm{Ga}_{0.3} \mathrm{~N} \\
(300 \mathrm{~nm})\end{array}$ & $\begin{array}{c}\mathrm{Al}_{0.7} \mathrm{Ga}_{0.3} \mathrm{~N} \\
(5 \mathrm{~nm})\end{array}$ & $\begin{array}{c}\mathrm{Al}_{0.12} \mathrm{Ga}_{0.88} \mathrm{~N} \\
(1.4-2.7 \mathrm{~nm})\end{array}$ & $255-303 \mathrm{~nm}$ \\
\hline (d) & 5-layer MQW & $\begin{array}{c}\mathrm{Al}_{0.53} \mathrm{Ga}_{0.47} \mathrm{~N} \\
(400 \mathrm{~nm})\end{array}$ & $\begin{array}{c}\mathrm{Al}_{0.53} \mathrm{Ga}_{0.47} \mathrm{~N} \\
(5 \mathrm{~nm})\end{array}$ & $\begin{array}{c}\mathrm{Al}_{0.11} \mathrm{Ga}_{0.89} \mathrm{~N} \\
(0-6.7 \mathrm{~nm})\end{array}$ & $272-343 \mathrm{~nm}$ \\
\hline
\end{tabular}

Then, we fabricated four series of AlGaN MQW samples, consisting of different $\mathrm{Al}$ content AlGaN barriers. Figure 3 shows an example of schematic layer structure. Table I summarizes the material and the thickness of buffer, barrier, well layers, and PL peak wavelength range of each series of AlGaN MQWs. In order to achieve a flat surface suitable for the growth of AlGaN quantum wells, an approximately 250-400 nm thick $\mathrm{AlN}(\mathrm{AlGaN})$ buffer layer followed by a very thin AlN layer was deposited. We confirmed a step-flow grown surface by atomic force microscopy (AFM) for the sample series (a), (b), and (c). After that, a five-layer MQW structure consisting of several-nm thick $\mathrm{Al}_{\mathrm{x}} \mathrm{Ga}_{1-\mathrm{x}} \mathrm{N}$ wells $(\mathrm{x}=0.11-0.18)$ and $5 \mathrm{~nm}$-thick $\mathrm{Al}_{\mathrm{y}} \mathrm{Ga}_{1-\mathrm{y}} \mathrm{N}$ barriers $(\mathrm{y}=0.53-1)$, and $10 \mathrm{~nm}$-thick $\mathrm{Al}_{\mathrm{y}} \mathrm{Ga}_{1-\mathrm{y}} \mathrm{N}$ cap $(\mathrm{y}=0.53-1)$ were grown. The well or barrier thickness is estimated simply from the growth rate of bulk material.

Figure 4 shows PL spectra of (a) AlN/Al $\mathrm{A}_{0.18} \mathrm{Ga}_{0.82} \mathrm{~N}$ and (b) $\mathrm{Al}_{0.80} \mathrm{Ga}_{0.20} \mathrm{~N} / \mathrm{Al}_{0.18} \mathrm{Ga}_{0.82} \mathrm{~N}$ five-layer MQWs for various well thickness, excited with Xe-lamp light source (215 nm) measured at $77 \mathrm{~K}$. The well thickness was varied ranging $1.2-3.3 \mathrm{~nm}$ and $0-3.3 \mathrm{~nm}$ for sample series (a) and (b), respectively. We obtained single-peak intense PL emission from each MQWs. The most efficient emission was obtained at the wavelength of 234 and 245 $\mathrm{nm}$ from $\mathrm{AlN} / \mathrm{Al}_{0.18} \mathrm{Ga}_{0.82} \mathrm{~N}$ and $\mathrm{Al}_{0.8} \mathrm{Ga}_{0.2} \mathrm{~N} / \mathrm{Al}_{0.18} \mathrm{Ga}_{0.82} \mathrm{~N}$ MQWs, respectively. The optimum value of well thickness was approximately $1.5 \mathrm{~nm}$. The PL intensity of the MQWs were several tens of times larger than that of AlGaN bulk.

The quantized level shift is obviously observed. The PL intensity heavily depends on the well thickness. The rapid reduction of the PL intensity with the increase of the well thickness may be caused by a reduction of the radiative recombination probability due to the large piezoelectric field in the well [6]. The reduction of the emission intensity for thin well may be mainly due to the increase of nonradiative recombination on the heterointerfaces. For the sample series (c) and (d), we observed the similar tendency obtained for (a) and (b).

Finally, the PL intensities are compared between AlGaN MQWs with various $\mathrm{Al}$ content of AlGaN barriers. Figure 5 shows the PL spectra of the samples (a)-(d) shown in Table I for optimized QW thickness measured at $77 \mathrm{~K}$. All samples were excited with Xe-lamp light source $(215 \mathrm{~nm})$ with the same excitation condition. From Fig. 5, we found that the most efficient emission is obtained around $245 \mathrm{~nm}$ for AlGaN MQW systems and that the optimum $\mathrm{Al}$ content for $\mathrm{AlGaN}$ barrier is $80 \%$. The PL intensity of QW is strongly depending on the buffer conditions. More efficient emission is expected from AlN/AlGaN QWs by improving the crystal quality of AlN buffer and barriers. We have also found that the PL intensity of AlGaN QWs is as strong as that of 
the $\mathrm{In}_{0.02} \mathrm{Ga}_{0.98} \mathrm{~N} / \mathrm{In}_{0.20} \mathrm{Ga}_{0.80} \mathrm{~N} \mathrm{QW}$ and much stronger than that of $\mathrm{Al}_{0.12} \mathrm{Ga}_{0.88} \mathrm{~N} / \mathrm{GaN}$ MQWs at $77 \mathrm{~K}$ [4]. However, at room temperature, the emission from AlGaN and GaN QWs are much weaker in comparison with InGaN QWs. The next subject is to obtain efficient UV emission at room temperature.

(a)

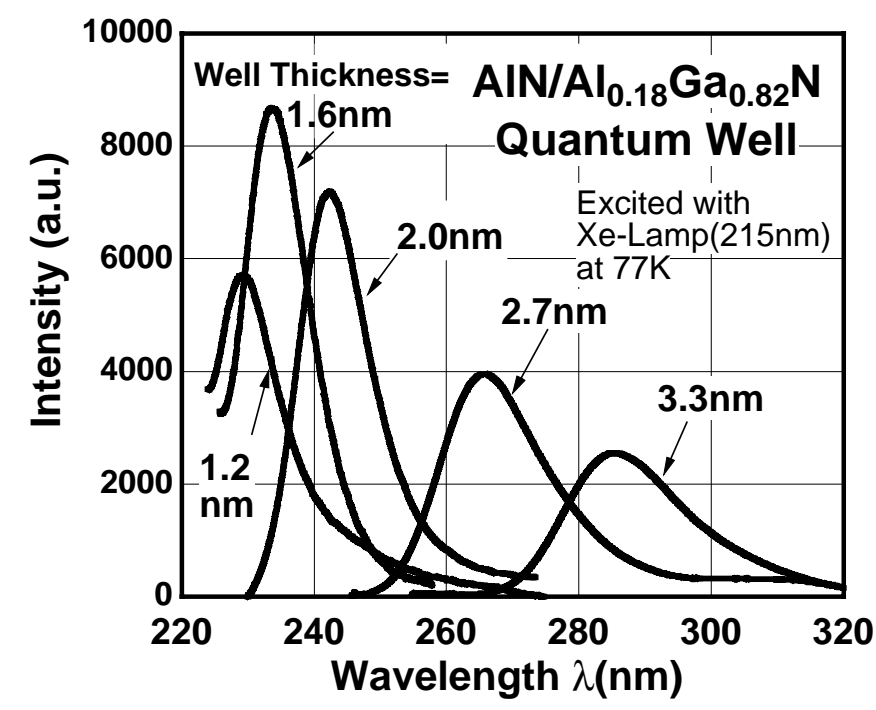

(b)

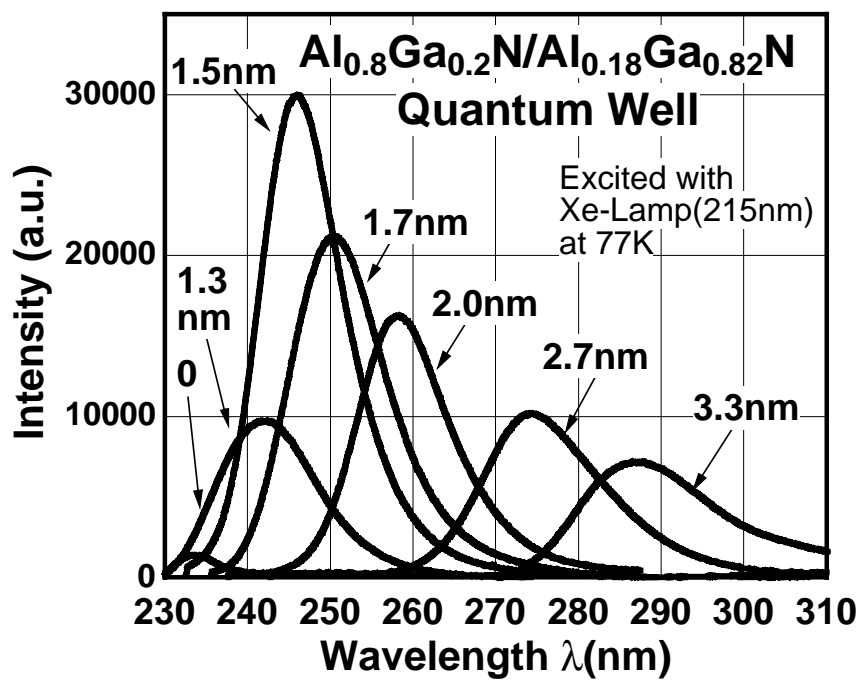

Figure 4. PL spectra of (a) AlN/Al $l_{0.18} G a_{0.82} \mathrm{~N}$ and (b) $A l_{0.80} G a_{0.20} N / A l_{0.18} G a_{0.82} N$ 5-layer $M Q W s$ for various well thickness. 


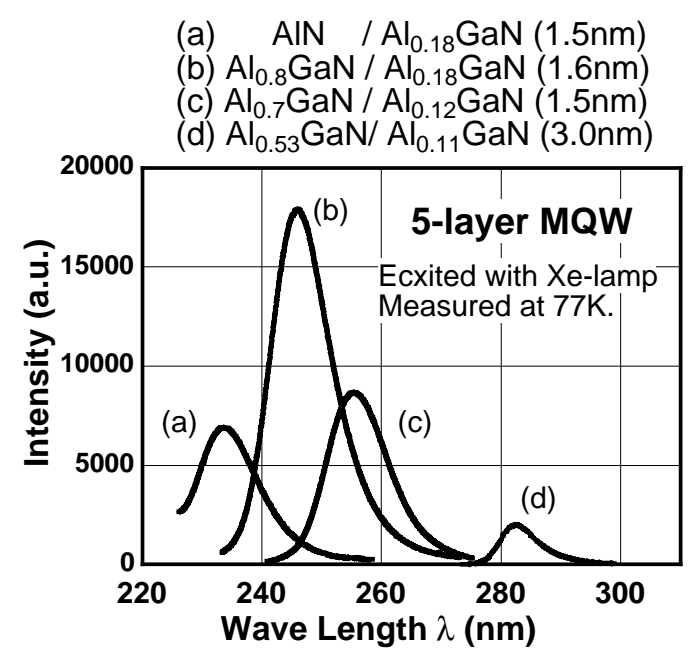

Figure 5. Comparison of $P L$ intensity at $77 \mathrm{~K}$ between AlGaN 5-layer MQWs with different Al content AlGaN barriers.

\section{CONCLUSION}

We demonstrated 230-250 nm efficient UV PL from AlN(AlGaN)/AlGaN MQWs fabricated by MOVPE. We showed PL spectra of high Al content AlGaN bulk (Al content: 85-95\%) emitting from near band-edge. We systematically investigated the PL properties of AlGaN-MQWs consisting of wide bandgap AlGaN (Al content: 53$100 \%$ ) barrier. We obtained efficient PL emission of 234 and $245 \mathrm{~nm}$ from AlN/Al $\mathrm{Al}_{0.18} \mathrm{Ga}_{0.82} \mathrm{~N}$ and $\mathrm{Al}_{0.8} \mathrm{Ga}_{0.2} \mathrm{~N} / \mathrm{Al}_{0.18} \mathrm{Ga}_{0.82} \mathrm{~N}$ MQWs, respectively, at $77 \mathrm{~K}$. The optimum value of well thickness was approximately $1.5 \mathrm{~nm}$. The emission from the AlGaN MQWs were several tens of times larger than that of bulk AlGaN. We found that the most efficient PL is obtained at around $240 \mathrm{~nm}$ from AlGaN MQWs with $\mathrm{Al}_{0.8} \mathrm{Ga}_{0.2} \mathrm{~N}$ barrier. Also, we found that the PL from AlGaN MQW is as efficient as that of InGaN QWs at $77 \mathrm{~K}$.

\section{REFERENCES}

1. Peter Kozodoy, Monica Hansen, S. P. DenBaars and U. K. Mishra, Appl. Phys. Lett. 74, 3681 (1999).

2. T. Mukai, H. Narimatsu and S. Nakamura, J. Crystal Growth 189/190, 778 (1998).

3. A. Kinoshita, H. Hirayama, M. Ainoya, A. Hirata and Y. Aoyagi, to be submitted.

4. H. Hirayama and Y. Aoyagi, Mater. Res. Soc. Proc. 537, G3.74 (1999).

5. A. Kinoshita, H. Hirayama, A. Hirata and Y. Aoyagi, International Conference on Solid State Device and Materials (SSDM), C-4-2, Tokyo (1999).

6. S. Chichibu, D. A. Cohen, M. P. Mack, A. C. Abare, P. Kozodoy, M. Minsky, S.

Fleischer, S. Keller, J. E. Bowers, U. K. Mishra, L. A. Coldren, D. R. Clarke and S. P. DenBaars, Appl. Phys. Lett. 73, 496 (1998). 